\title{
PENGEMBANGAN MODEL PERENCANAAN PENDIDIKAN
}

\author{
Fatkhul Mubin \\ fatkhulmubin90@gmail.com
}

\begin{abstract}
Abstrak
Perencanaan pendidikan adalah suatu proses menetapkan keputusan yang berkaitan dengan tujuan yang akan dicapai, sumber sumber yang akan diberdayakan, dan teknik atau metode akan dipilih secara tepat untuk melaksanakan tindakan selama kurun waktu tertentu agar penyelenggaraan pendidikan dapat dilaksanakan secara efektif, efisien dan bermutu. Depdikbud (1982), mengemukakan langkah-langkah yang ditempuh dalam proses penyususnan perencanaan pendidikan yaitu: (a) pengumpulan dan pengolahan data, (b) diagnosis, (c) perumusan kebijakan, (d) perkiraan kebutuhan masa depan, (e) perhtungan biaya, (f) penetapan sasaran, (g) perumsan rencana, (h) perincian rencana, (i) implementasi rencana, (j) evaluasi rencana, dan (k) revisi rencana. Dengan adanya langkah-langkah perencanaan pendidikan tersebut diharapkan pendidikan di Indonesia akan semakin maju. Masalah pendidikan di Indonesia seakan menjadi masalah pula untuk pemerintah dalam merencanakan Sistem Pendidikan Nasional. Sistem Pendidikan Nasional selama ini seakan belum meng-cover tujuan pendidikan nasional. Tujuan pendidikan nasional begitu mulia, tetapi implementasinya tidak sanggup mewujudkannya. Perencanaan sistem pendidikan ini akan sesuai dengan tujuan pendidikan nasional, apabila masalah dalam pendidikan yang telah dibahas dapat teratasi. ${ }^{1}$
\end{abstract}

\section{PENDAHULUAN}

Dalam suatu kegiatan apa pun bentuknya, perencanaan (planning) adalah faktor yang sangat penting dan strategis sifatnya sebagai pemandu arah bagi pelaksanaan suatu kegiatan dalam rangka mencapai tujuan/ sasaran/target yang diinginkan. Perencanaan sebagai suatu rangkaian proses kegiatan, dilakukan untuk menyiapkan keputusan mengenai apa yang diharapkan terjadi dan apa yang akan dilakukan. Pada dasarnya perencanaan memiliki makna yang sangat kompleks. Perencanaan dapat didefinisikan dalam berbagai macam pengertian, tergantung perspektif yang dipakai serta latar belakang yang memengaruhi seseorang dalam mendefinisikannya. Dalam pengertian yang luas, perencanaan dapat dimaknai sebagai suatu \footnotetext{
DIDIKAN

${ }^{1}$ https://www.researchgate.net/publication/335504424_TEKNIK_DAN_MODEL_PERENCANAAN_PEN
} 
proses mempersiapkan kegiatan-kegiatan secara sistematis yang akan dilakukan untuk mencapai tujuan tertentu.

Dalam bidang pendidikan Islam, perencanaan merupakan salah satu faktor kunci efektivitas terlaksananya kegiatan pendidikan demi tercapainya tujuan pendidikan yang diharapkan bagi setiap jenjang dan jenis pendidikan pada tingkat nasional maupun lokal. Pentingnya perencanaan yang baik dalam bidang pendidikan Islam adalah oleh karena pendidikan Islam diyakini oleh umat Islam sebagai jalan hidup manusia yang paling baik. Sebagai jalan yang paling baik, pendidikan Islam perlu direncanakan secara baik dan sistematis, sehingga Pendidikan Islam benar-benar dapat menyejahterakan setiap Muslim, baik di dunia maupun di akhirat. Namun dalam praktek pelaksanaan pendidikan Islam, faktor perencanaan pendidikan baru atau masih lebih banyak dijadikan faktor pelengkap, sehingga sering kali tujuan yang telah ditetapkan tidak tercapai secara maksimal. Penyebabnya adalah karena para perencana pendidikan kurang memahami proses dan mekanisme perencanaan dalam konteks yang lebih komprehensif. Selain itu, posisi bidang perencanaan belum merupakan faktor kunci keberadaan suatu lembaga pendidikan, baik pada tingkat makro maupun mikro. Karena itu, peran perencanaan pendidikan terhadap pencapaian visi, misi, dan tujuan lembaga pendidikan belum dirasakan secara optimal. ${ }^{2}$

\section{PEMBAHASAN}

\section{A. Perencanaan dan Manajemen Pendidikan}

Secara konseptual, manajemen pendidikan meliputi perencanaan, pelaksanaan, pengendalian, dan pengawasan mengenai (sumber daya manusia, sumber belajar, kurikulum, dana, dan fasilitas) untuk mencapai tujuan pendidikan secara efektif dan efisien (Engkoswara 1987; ISPI 1995; Manap 1999, 2008). ${ }^{3}$ Perencanaan pendidikan

${ }^{2}$ Saihu, S. (2019). RINTISAN PERADABAN PROFETIK UMAT MANUSIA MELALUI PERISTIWA TURUNNYA ADAM AS KE-DUNIA. Mumtaz: Jurnal Studi Al-Quran dan Keislaman, 3(2), 268-279, Saihu, S. (2019). Pendidikan Pluralisme Agama: Kajian tentang Integrasi Budaya dan Agama dalam Menyelesaikan Konflik Sosial Kontemporer. Jurnal Indo-Islamika, 9(1), 67-90, Saihu, S. (2019). IMPLEMENTASI MANAJEMEN BALANCED SCORECARD DI PONDOK PESANTREN JAM'IYYAH ISLAMIYYAH TANGERANG SELATAN. Mumtaz: Jurnal Studi Al-Quran dan Keislaman,3(1), 1-22. Saihu, S. (2019). KOMUNIKASI PENDIDIK TERHADAP ANAK BERKEBUTUHAN KHUSUS DI SEKOLAH KHUSUS ASY-SYIFA LARANGAN. Andragogi: Jurnal Pendidikan Islam danManajemen Pendidikan Islam, 1(3), 418-440. Saihu, S., \& Marsiti, M. (2019). PENDIDIKAN KARAKTER DALAM UPAYA MENANGKAL RADIKALISME DI SMA NEGERI 3 KOTA DEPOK, JAWA BARAT. Andragogi: Jurnal Pendidikan Islam dan Manajemen Pendidikan Islam, 1(1), 23-54. Saihu, S. (2019). KONSEP MANUSIA DAN IMPLEMENTASINYA DALAM PERUMUSAN TUJUAN PENDIDIKAN ISLAM MENURUT MURTADHA MUTHAHHARI. Andragogi: Jurnal Pendidikan Islam dan Manajemen Pendidikan Islam, 1(2), 197-217. Saihu, S., \& Rohman, B. (2019). PEMBENTUKAN KARAKTER MELALUI MODEL PENDIDIKAN TRANSFROMATIFE LEARNING PADA SANTRI DI PONDOK PESANTREN NURUL IKHLAS BALI. Edukasi Islami: Jurnal Pendidikan Islam, 8(02), 435-452.

${ }^{3}$ Saihu, S., \& Taufik, T. (2019). PERLINDUNGAN HUKUM BAGI GURU. Al Amin: Jurnal Kajian Ilmu dan Budaya Islam, 2(2), 105-116. Saihu, S. (2020). KONSEP PEMBAHARUAN PENDIDIKAN ISLAM MENURUT FAZLURRAHMAN. Andragogi: Jurnal Pendidikan Islam dan Manajemen Pendidikan Islam, 2(1), 8295.Saihu, S. (2020). ETIKA MENUNTUT ILMU MENURUT KITAB TA'LIM MUTA'ALIM. Al Amin: Jurnal Kajian Ilmu dan Budaya Islam, 3(1), 99-112. Saihu, Aziz, A., Mubin, F., \& Sarnoto, A. Z. (2020). Design of islamic 
mempunyai peran penting dan berada pada tahap awal dalam proses manajemen pendidikan, yang dijadikan sebagai panduan bagi pelaksanaan, pengendalian, dan pengawasan penyelenggaraan pendidikan. Perencanaan merupakan suatu proyeksi tentang apa yang harus dilaksanakan guna mencapai sasaran dan tujuan yang telah ditetapkan (Kaufman 1972; Hadikumoro 1980).

Sebagai suatu proyeksi, perencanaan memiliki unsur kegiatan mengidentifikasi, menginventarisasi dan menyeleksi kebutuhan berdasarkan skala prioritas, mengadakan spesifikasi yang lebih rinci mengenai hasil yang akan dicapai, mengidentifikasi persyaratan atau kriteria untuk memenuhi setiap kebutuhan, serta mengidentifikasi kemungkinan alternatif, strategi, dan sasaran bagi pelaksanaannya. Kebutuhan terhadap perencanaan pendidikan diakibatkan oleh adanya kompleksitas masyarakat dewasa ini, seperti masalah jumlah penduduk, kebutuhan akan tenaga kerja, masalah lingkungan, dan adanya keterbatasan sumber daya alam. Hal tersebut antara lain dikemukakan Banghart dan Trull (1973:5) dalam bukunya yang menyatakan bahwa: "The need for planning arose with the intensified complexcities of modern technological society. Problems such as population, manpower needs, ecology, decreasing natural resources and haphazard aplication of scientific developments all place demand on educational institutions for solution". 4

Sampai saat ini, pendidikan di Indonesia masih mengalami krisis besar karena perkembangan dan kebutuhan akan pendidikan tidak dapat terpenuhi oleh sumbersumber yang tersedia. Sejak beberapa tahun lalu, Coombs (1968) dan Manap (1999, 2008) menghimbau agar pendidikan direncanakan secara seksama. Caranya dengan melihat pada keterbatasan yang ada dan diarahkan kepada penyelenggaraan pendidikan yang lebih sesuai dengan kebutuhan perkembangan masyarakat. Untuk mengatasi

education based on local wisdom (An analysis of social learning theories in forming character through ngejot tradition in bali). International Journal of Advanced Science and Technology, 29(6), 1278-1293. Ronaldo, R., Zulfikar, A., Saihu, Ismail, \& Wekke, I. S. (2020). International relations of the asia pacific in the age of trump. Journal of Environmental Treatment Techniques, 8(1), 244-246. Saihu, M. M., \& Aziz, A. (2020). Implementasi Metode Pendidikan Pluralisme Dalam Mata Pelajaran Pendidikan Agama Islam. Belajea; Jurnal Pendidikan Islam, 5(1), 131-150. Saihu, M. (2019). Urgensi 'Urf dalam Tradisi Male dan Relevansinya dalam Dakwah Islam di Jembrana-Bali. Jurnal Bimas Islam, 12(1), 173-201. Saihu, S. (2020). The Effect of Using Talking Stick Learning Model on Student Learning Outcomes in Islamic Primary School of Jamiatul Khair, Ciledug Tangerang. Tarbawi: Jurnal Keilmuan Manajemen Pendidikan, 6(01), 61-68. Saihu, S. (2020). Pendidikan sosial yang terkandung dalam Surat At-Taubah Ayat 71-72. Edukasi Islami: Jurnal Pendidikan Islam, 9(01), 127-148.

${ }^{4}$ Aziz, A., \& Saihu, S. (2019). Interpretasi Humanistik Kebahasaan: Upaya Kontekstualisasi Kaidah Bahasa Arab. Arabiyatuna: Jurnal Bahasa Arab, 3(2), 299-214. Saihu, S. (2019). PENDIDIKAN KARAKTER BERBASIS KEARIFAN LOKAL (STUDI DI JEMBRANA BALI). Edukasi Islami: Jurnal Pendidikan Islam, 8(01), 69-90. Şahin, C. RELIGIA.Saihu, S., \& Mailana, A. (2019). Teori pendidikan behavioristik pembentukan karakter masyarakat muslim dalam tradisi Ngejot di Bali. Ta'dibuna: Jurnal Pendidikan Islam, 8(2), 163-176. Mubin, F. KEADILAN DALAM GENDER: KAJIAN KEPEMIMPINAN WANITA DALAM ISLAM1, Saihu, M. (2019). Merawat Pluralisme Merawat Indonesia (Potret Pendidikan Pluralisme Agama Di Jembrana-Bali). Deepublish. Mubin, F. (2019). TAFSIR EMANSIPATORIS: PEMBUMIAN METODOLOGI TAFSIR PEMBEBASAN. Mumtaz: Jurnal Studi Al-Quran dan Keislaman, 3(1), 131-151. Mubin, F. MODEL-MODEL PEMBELAJARAN BERBASIS MADRASAH DAN KEGIATAN LAIN YANG DIPERLUKAN DI DALAMNYA (FAKTOR PENDUKUNGNYA). 
permasalahan pendidikan secara komprehensif, Banghart dan Trull (1973:120) merekomendasikan beberapa hal yang harus dicermati dalam merencanakan pendidikan, di antaranya :

1. Mengidentifikasi berbagai kebijakan terkait dengan sistem pendidikan.

2. Mengevaluasi dan mempertimbangkan berbagai alternatif metode pendidikan dan dalam kaitannya dengan masalah-masalah khusus pendidikan;

3. Mencermati masalah-masalah kritis yang memerlukan perhatian, penelitian, dan pengembangan.

4. Mengevaluasi keunggulan dan kelemahan sistem pendidikan yang ada; serta

5. Melaksanakan kajian terhadap sistem pendidikan dan komponen-komponennya. Perencanaan berfungsi sebagai pemberi arah bagi terlaksananya aktivitas yang disusun secara komprehensif, sistematis, dan transparan. Perencanaan yang baik adalah perencanaan yang paling mungkin untuk dilaksanakan. Melalui perencanaan dapat dijelaskan tujuan yang akan dicapai, ruang lingkup pekerjaan yang akan dijalankan, orang-orang yang terlibat dalam pekerjaan itu, berbagai sumber daya yang diperlukan, serta langkah-langkah dan metode kerja yang dipilih berdasarkan urgensi dan prioritasnya. Semua itu menjadi arah dan panduan dalam mengorganisir unsur manusia dalam pendidikan, pengerahan, dan pemanfaatan berbagai sumber daya guna menunjang proses pencapaian tujuan dan dapat dijadikan sebagai alat pengendalian tentang pencapaian tujuan. Kekeliruan dan kesalahan semestinya dapat dihindari dengan adanya rencana yang komprehensif, terintergrasi, dan berdasarkan pada pemilihan strategi yang tepat. Ketepatan dan keberhasilan dalam perencanaan menjadi barometer suksesnya pelaksanaan kegiatan dan bermaknanya proses pengendalian kegiatan serta menjadi kunci bagi efisiensi pemanfaatan berbagai sumber daya dan efektivitas dalam pencapaian tujuan. ${ }^{5}$

\section{B. Model Perencanaan Pendidikan}

Menurut Kamus Besar Bahasa Indonesia, kata model diartikan sebagai contoh, pola acuan ragam, macam, atau barang tiruan yang kecil dan tepat seperti yang ditiru. Jadi model perencanaan pendidikan dapat diartikan sebagai contoh atau acuan yang digunakan dalam penyusunan sebuah perencanaan, lebih umum membahas rencana dan kebijakan tertinggi dalam instansi pendidikan. Menurut Suprayogi (2014) model dan metode perencanaan pendidikan tentunya berbeda dengan model dan metode perencanaan pengajaran, perencanaan pendidikan cakupannya lebih luas dan lebih umum menyangkut rencana dan kebijakan yang dikeluarkan oleh pengambil kebijakan tertinggi dalam instansi pendidikan. Sedangkan model perencanaan pengajaran memuat komponen sistem pembelajaran dan unsur kegiatan yang dilakukan, baik oleh guru maupun siswa dalam proses pembelajaran. Ada beberapa macam-macam model perencanaan dalam pendidikan yaitu seperti berikut:

\footnotetext{
${ }^{5}$ Dr. Manap Somantri, M.Pd, Perencanaan Pendidikan, (Bogor: IPB Press, 2014), hal 1-3
} 


\section{Model Perencanaan Komprehensif}

Model ini digunakan untuk menganalisis perubahan-perubahan dalam sistem pendidikan secara keseluruhan. Selain itu berfungsi sebagai suatu patokan dalam menjabarkan rencana-rencana yang lebih spesifik ke arah tujuan-tujuan yang lebih luas. Model ini berfungsi sebagai patokan dalam menjabarkan rencana-rencana yang lebih spesifik atau khusus ke arah tujuan yang lebih global dan luas. Metode ini juga dapat digunakan untuk menganalisis perubahan secara luas dalam suatu sistem pendidikan secara menyeluruh. ${ }^{6}$

\section{a. Model Target Setting}

Model ini diperlukan dalam upaya melaksanakan proyeksi atau memperkirakan tingkat perkembangan dalam kurun waktu tertentu. Dalam persiapannya dikenal model untuk analisis demografis dan proyeksi penduduk, model untuk memproyeksikan jumlah siswa yang terdaftar dalam sekolah, dan model untuk memproyeksikan kebutuhan tenaga kerja.

b. Model Pembiayaan dan Efektivitas Biaya

Model ini digunakan untuk menganalisis proyek-proyek dalam kriteria efisien dan efektivitas ekonomis. Dengan model ini dapat diketahui proyek yang paling fisibel dan memberikan suatu perbandingan yang paling baik di antara proyek-proyek yang menjadi alternatif penanggulangan masalah yang dihadapi. Penggunaan model ini dalam pendidikan didasarkan pada pertimbangan bahwa pendidikan itu tidak terlepas dari masalah pembiayaan. Dan dengan sejumlah biaya yang dikeluarkan selama proses pendidikan diharapkan dapat memberikan keuntungan tertentu. Penggunaan model ini dalam pendidikan didasarkan bahwa pendidikan tidak terlepas dari biaya yang diharapkan membawa keuntungan atau benefit. Dapat dikatakan model ini sama dengan model untung rugi.

c. Model PPBS PPBS (Planning, Programming, Budgetting System), dalam bahasa Indonesia adalah sistem perencanaan, penyusunan program, dan penganggaran (SP4).

Model Planning, Programming, Budgeting, System;atau biasa disebut dengan PPBS merupakan sebuah sistem yang tidak bisa terpisahkan, dimana dalam perencanaan tujuan harus dikembangkan pada program-program, kemudian mempertimbangkan masalah pembiayaan yang akan dipilih sebagai alternatif yang paling baik. Artinya dalam perencanaan pendidikan harus melihat pada semua aspek secara komperhensif sehingga mendapatkan sebuah keputusan terbaik.

\footnotetext{
${ }^{6}$ Fattah Nanang dalam Endin Mujahidin Dkk, Perencanaan Pendidikan, Bogor, Program Pasca Srajana UIKA Bogor, 2009, Hlm. 55.
} 
Untuk memahami PPBS secara baik, ada beberapa sifat-sifat esensial dari sistem ini. Esensi dari sistem ini adalah (a) merinci secara cermat dan menganalisis tujuan yang akan dicapai (b) mencari alternatif-alternatif terbaik untuk mencapai tujuan (c) menggambarkan pembiayaan total dari seluruh proses, baik secara langsung ataupun tidak (d) menggambarkan efektifitas dari setiap alternatif sehingga dapat lebih mudah mencapai tujuan yang diinginkan (e) membandingkan semua alternatif dan memilihnya, mana yang paling baik untuk mencapai tujuan. ${ }^{7}$

Menurut Fattah (2013: 51) model ini bermakna bahwa perencanaan, penyusunan program, dan penganggaran dipandang sebagai suatu sistem yang komprehensif untuk pengambilan keputusan yang efektif. Untuk memahami PPBS secara baik, maka perlu kita perhatikan sifat-sifat esensial dari sistem ini. Esensi dari PPBS adalah sebagai berikut:

a. Memerinci secara cermat dan menganalisis secara sistematik terhadap tujuan yang hendak dicapai.

b. Mencari alternatif-alternatif yang relevan, cara yang berbeda-beda untuk mencapai tujuan.

c. Menggambarkan biaya total dari setiap alternatif, baik biaya langsung ataupun tidak langsung, biaya yang telah lewat ataupun yang akan datang, baik biaya yang berupa uang ataupun biaya yang tidak berupa uang.

d. Memberikan gambaran tentang efektifitas setiap alternatif dan bagaimana alternatif itu mencapai tujuan.

e. Membandingkan dan menganalisis alternatif tersebut, yaitu mencari kombinasi yang memberikan efektifitas yang paling besar dari sumber yang ada dalam pencapain tujuan (Jujun S., 1980). Model ini bermakna bahwa perencanaan, penyusunan program, dan penganggaran dipandang sebagai suatu sistem yang tak terpisahkan satu sama lainnya. PPBS merupakan suatu proses yang komprehensif untuk pengambilan keputusan yang lebih efektif. Menurut Kast dan Rosenwzweig (1979) PPBS merupakan suatu pendekatan yang sistematik yang berusaha untuk menetapkan tujuan, mengembangkan program-program untuk dicapai, menemukan besarnya biaya dan alternatif, dan menggunakan proses penganggaran yang merefleksikan kegiatan program jangka panjang. Harry J. Hartley (1968) mengemukakan bahwa PPBS merupakan proses perencanaan yang komprehensif yang meliputi program budget sebagai komponen utamanya. Ciri-ciri SP4 (sistem perencaan penyusunan program dan penganggaran) menurut Timan (2004) adalah sebagai berikut:

\footnotetext{
${ }^{7}$ Endin Mujahidin Dkk, Perencanaan Pendidikan, Hlm. 55.
} 
1. SP4 dimulai dari penetapan tujuan nasional. Jadi perencanaan dengan SP4 bersifat dari atas ke bawah (top down).

2. Menghubungkan tujuan umum dengan program yang bersifat khusus.

3. Menghubungkan program dengan sumber-sumber yang diperlukan.

4. Menghubungkan masukan instrumental dengan uang yang diperlukan.

Tujuan penggunaan SP4 (sistem perencaan penyusunan program dan penganggaran) menurut Timan (2004) adalah sebagai berikut:

1. Membuat agar perencanaan jangka panjang merupakan kegiatan rutin.

2. Memungkinkan rencana dan program dapat ditinjau kembali setiap saat untuk dapat diadakan revisi.

3. Mengadakan klasifikasi kegiatan organisasi dalam bentuk program dan hasil yang diharapkan dan bukan lagi berdasarkan jumlah jabatan atau yang hal-hal lain.

4. Meningkatkan koordinasi antar berbagai program yang dirancang untuk mencapai tujuan. 5. Mendorong perencanaan terpadu antar Departemen/ bagian.

5. Memungkinkan pengukuran kemajuan suatu program sesuai dengan pertahapannya. $^{8}$

\section{Konsep Perencanaan Pendidikan}

Perencanaan pendidikan adalah suatu proses menetapkan keputusan yang berkaitan dengan tujuan yang akan dicapai, sumber sumber yang akan diberdayakan, dan teknik atau metode akan dipilih secara tepat untuk melaksanakan tindakan selama kurun waktu tertentu agar penyelenggaraan pendidikan dapat dilaksanakan secara efektif, efisien dan bermutu. Depdikbud (1982), mengemukakan langkah-langkah yang ditempuh dalam proses penyususnan perencanaan pendidikan yaitu:

a. Pengumpulan dan pengolahan data,

b. Diagnosis,

c. Perumusan kebijakan,

d. Perkiraan kebutuhan masa depan,

e. Perhtungan biaya,

f. Penetapan sasaran,

g. Perumsan rencana,

h. Perincian rencana,

i. Implementasi rencana,

j. Evaluasi rencana, dan

k. Revisi rencana. 
Dengan adanya langkah-langkah perencanaan pendidikan tersebut diharapkan pendidikan di Indonesia akan semakin maju. Masalah pendidikan di Indonesia seakan menjadi masalah pula untuk pemerintah dalam merencanakan Sistem Pendidikan Nasional. Sistem Pendidikan Nasional selama ini seakan belum meng-cover tujuan pendidikan nasional. Tujuan pendidikan nasional begitu mulia, tetapi implementasinya tidak sanggup mewujudkannya. Perencanaan sistem pendidikan ini akan sesuai dengan tujuan pendidikan nasional, apabila masalah dalam pendidikan yang telah dibahas dapat teratasi. $^{9}$

Perencanaan juga dapat di definisiskan sebagai proses pemilihan dan penetapan tujuan, stategi, metode, anggaran, dan standar atau tolok ukur keberhasilan sesuatu kegiatan. ${ }^{10}$ Pengertian tersebut menunjukkan bahwa prencanaan merupakan proses atau rangkaian beberapa kegiatan yang saling berhubungan dalam memilih salah satu di antara beberapa alternatif tentang tujuan yang ingin dicapai oleh suatu organisasi. Kemudian memilih strategi dan metode untuk mencapai tujuan tersebut. Sementara itu, menurut Ritha F. Dalimunthe ${ }^{11}$ perencanaan adalah pemilihan dan penetapan kegiatan, selanjutnya apa yang harus dilakukan, kapan, bagaimana dan oleh siapa. Perencanaan adalah suatu proses yang tidak berakhir bila rencana tersebut telah ditetapkan; rencana haruslah diimplementasikan. Setiap saat selama proses implementasi dan pengawasan, rencanarencana mungkin memerlukan perbaikan agar tetap berguna. "Perencanaan kembali" kadang-kadang dapat menjadi faktor kunci agar mampu menyesuaikan diri dengan situasi dan kondisi baru secepat mungkin.

Conyers \& Hills ${ }^{12}$ mendefinisikan "perencanaan" sebagai "suatu proses yang bersinambungan", yang mencakup "keputusankeputusan atau pilihan-pilihan berbagai aiternatif penggunaan sumber daya untuk mencapai tujuan-tujuan tertentu pada masa yang akan datang." Dari pengertian-pengertian tersebut, maka perencanaan pendidikan dimaksudkan untuk mempersiapkan semua komponen pendidikan, agar dapat terlaksana proses belaj ar mengaj ar yang baik dalam penyelenggaraan pendidikan dalam mencapai sasaran keluaran pendidikan seperti yang diharapkan. Pengorganisasian pendidikan ditujukan untuk menghimpun semua potensi komponen pendidikan dalam suatu organisasi yang sinergis untuk dapat menyelenggarakan pendidikan dengan sebaikbaiknya.

Kegiatan pendidikan adalah pelaksanaan dari penyelenggaraan pendidikan yang telah direncanakan dan diselenggarakan oleh organisasi penyelenggara pendidikan dengan

\footnotetext{
DIDIKAN

${ }^{10}$ Hadari Nawawi. Perencanaan SDM untuk Organiasi Profit. Yogyakarta: Gadjah Mada University. 2001

${ }^{11}$ Ritha F Dalimunthe, Keterkaitan antara Penelitian Manajemen dengan Pendidikan dan Pengembangan Ilmu Manajemen. Medan: Universitas Sumatra Utara, 2003.

${ }^{12}$ Conyers \& Hills, Creative Human Resource Planning and Applications : A Strategic Approach. New York Prectice Hall, Inc, 1994.
}

${ }^{9}$ https://www.researchgate.net/publication/335504424_TEKNIK_DAN_MODEL_PERENCANAAN_PEN 
memparhatikan rambu-rambu yang telah ditetapkan dalam perencanaan dalam rangka mencapai hasil keluaran pendidikan yang optimal. Pengendalian pendidikan dimaksudkan untuk menjaga agar penyelenggaraan pendidikan dilaksanakan sesuai yang direncanakan dan semua komponen pendidikan digerakkan secara sinergis dalam proses yang mengarah kepada pencapaian tujuan pendidikan yang dijabarkan dalam sasaransasaran menghasilkan keluaran secara optimal seperti yang telah ditetapkan dalam perencanaan pendidikan. Menurut John R. Kelly ${ }^{13}$ perencanaan pendidikan tersebut mengedepankan 4 unsur dasar perencanaan, yaitu:

1. Pemilihan Merencanakan berarti memilih. Perencanaan merupakan proses memilih di antara berbagai kegiatan yang diinginkan, karena tidak semua yang diinginkan itu dapat dilakukan dan dicapai dalam waktu yang bersamaan. Hal itu menyiratkan bahwa hubungan antara perencanaan dan proses pengambilan keputusan sangat erat. Oleh karena itu, banyak buku mengenai perencanaan membahas pendekatan-pendekatan alternatif dalam proses pengambilan keputusan, terutama yang berkaitan dengan faktor-faktor yang mempengaruhi pengambilan keputusan dan urutan tindakan di dalam proses pengambilan keputusan;

2. Sumber daya Perencanaan merupakan alat pengalokasian sumber daya. Penggunaan istilah sumber daya di sini menunjukkan segala sesuatu yang dianggap berguna dalam pencapaian suatu tujuan tertentu. Sumber daya di sini mencakup sumber daya manusia; sumber daya alam, sumber daya modal dan keuangan. Perencanaan mencakup proses pengambilan keputusan tentang bagaimana sumber daya yang tersedia itu digunakan sebaik-baiknya. Oleh karena itu, kuantitas dan kualitas sumber daya tersebut sangat berpengaruh dalam proses memilih di antara berbagai pilihan tindakan yang ada;

3. Tujuan Perencanaan merupakan alat untuk mencapai tujuan. Konsep perencanaan sebagai alat pencapaian tujuan muncul berkenaan dengan sifat dan proses penetapan tujuan. Salah satu masalah yang sering dihadapi oleh seorang perencana adalah bahwa tujuan-tujuan mereka kurang dapat dirumuskan secara tepat. Sering kali tujuan-tujuan tersebut didefinisikan secara kurang tegas, karena kadang kala tujuan-tujuan tersebut ditetapkan oleh pihak lain.; dan

4. Waktu Perencanaan mengacu ke masa depan. Salah satu unsur penting dalam perencanaan adalah unsur waktu. Tujuan-tujuan perencanaan dirancang untuk dicapai pada masa yang akan datang. Oleh karena itu, perencanaan berkaitan dengan masa depan.

\section{Model dan Metode Perencanaan Sekolah Berbasis Islam-Kemasyarakatan}

Tujuan pendidikan nasional yang tertuang dalam UU no 20 tahun 2003 adalah mengembangkan potensi peserta didik agar menjadi manusia yang beriman dan bertakwa kepada Tuhan Yang Maha Esa, berakhlak mulia, sehat, berilmu, cakap, kreatif, mandiri,

\footnotetext{
${ }^{13}$ John R. Kelly. 1993. Leisure. Englewood Cliffs, NJ: Prentice-Hall, Inc.
} 
dan menjadi warga negara yang demokratis serta bertanggung jawab. Sejatinya manusia yang telah dibekali dengan ilmu pengetahuan baru akan dihitung kemanfaatannya setelah dapat mengamalkan ilmunya bagi orang disekitarnya.

Pendidikan Islam mengajarkan bagaimana menjadi manusia yang baik yaitu dengan mencirikan manusia yang paling banyak memiliki nilai manfaat buat orang lain. ${ }^{14}$ Pentingnya responsibilitas sosial dalam Islam yaitu intuk menjamin terbentuknya fondasi-fondasi yang kuat bagi masa depan masyarakat yang Islami berdasarkan Alqur'an dan hadits. Karena dengan dasar itu dapat membentuk masayarakat yang bebas dari kriminalitas ${ }^{15}$. Pada sisi lain, hasil dari pendidikan seharusnya membuahkan perubahan bagi masyarakat luas. Pendidikan bagi anak-anak dapat menjadi alternatif yang baik untuk memajukan masyarakat menjadi masyarakat madani. Persoalan dimasyarakat dapat dipecahkan dan diselesaikan karena orang-orang yang berpendidikan, dimana sebagai orang terdidik memiliki perbedaan cara pandang dan berfikir. Banyak permasalahan dimasarakat tidak hanya dapat diselesaikan dengan pendidikan. Hal ini disebabkan karena pendidikan tidak diarahkan untuk menyelesaikan persoalanpersoalan dimasayarakat. Terlebih lagi pendidikan Islam yang justru sangat penting ini belum memiliki fokus sebagai problem solver dimasyarakat. Untuk itulah penting mendesain perencanaan lembaga pendidikan berbasis Islam-Kemasyarakatan dengan menelisik model dan metode terbaik.Jika menggunakan model PPBS maka dapat dirancang sebuah perencanaan yang berhubungan dengan:

Tujuan daripada sekolah berbasis Islam-Kemasyarakatan adalah (a) menumbuhkan jiwa sosial yang peka terhadap permasalahan di masyarakat (b) menumbuhkan kesadaran akan tanggung jawab moral terhadap masayarakat (c) menciptakan generasi yang siap terjun dimasyarakat dengan hard dan soft skill nya (d) menciptakan generasi Islam yang memiliki nilai tinggi pada aspek keagamaan yang matang dalam ilmu dan amal.

Fakta yang terjadi saat ini adalah tidak bertanggung jawabnya pendidikan sedari dini terhadap permasalahan di masyarakat. Padahal dengan banyaknya persoalan sosial, ekonomi, dan budaya dimasayarakat baik kota maupun desa dapat dijadikan media pembelajaran disekolah untuk belajar mencari tahu permasalahan dan mencari solusinya oleh siswa. Dengan demikian mereka akan belajar bagaimana menghadapi masalah tersebut. Tentu dari jenjang yang paling rendah pengajarannya harus lebih sederhana.

Jika menggunakan metode cause-effect (sebab-akibat), maka cara yang harus ditempuh untuk mencapai tujuan agar siswa memiliki jiwa sosial yang peka terhadap masalah masyarakat adalah: melibatkan dalam kegiatan masyarakat. Seperti kerja bakti,

14 "Sebaik-baik manusia adalah yang paling bermanfaat bagi orang lain.” (Hadits Riwayat ath-Thabrani, Al-Mu'jam al-Ausath, juz VII, hal. 58, dari Jabir bin Abdullah r.a.. Dishahihkan Muhammad Nashiruddin al-Albani dalam kitab: As-Silsilah Ash-Shahîhah)

${ }^{15}$ Ali Abdul Halim Mahmud, Fikih Responsibilitas dan tanggung Jawab Muslim, Jakarta, Gema Insani Press, 2000, Hlm. 194-195. 
mengurus pemberdayaan masjid, mengurus jenazah, memperbaiki saluran irigasi petani, rapat dengan pihak desa dan lain sebagainya. Pengalaman riil tersebut dibutuhkan bagi siswa nanti saat dewasa bagaimana bermasyarakat mengurus kepentingan umum di masyarakat. Sehingga ilmu-ilmu yang didapatkan dibangku sekolah baik yang bersifat teoritis dan praktis langsung dapat digunakan jika dibutuhkan.

Kemudian cara yang harus ditempuh agar siswa memiliki jiwa dan tangungung jawab moral adalah dengan memberikan tanggung jawab sejak dini di masyarakat. Sekecil apapun mereka sudah harus diajarkan bertangunggung jawab, sehingga mereka merasa keberadaan mereka sangat dibutuhkan kelak.

Kemudian untuk mempersiapkan generasi yang siap terjun di masyarakat dengan hard dan soft skill adalah dengan mengajarkan pengetahuan-pengetahuan dan skill apa saja yang di butuhkan di masyarakat. Yang paling sederhana adalah mereka diajarkan menjadi imam shalat, sampai pada masalah yang membutuhkan keahlian khusus seperti pembuatan tata ruang desa, sarana irigasi, perencanaan program desa dan lain sebagainya.

Yang terakhir adalah ingin menjadikan manusia yang memiliki nilai tinggi pada aspek keagamaan serta matang dalam bidang ilmu dan amal. Cara yang dapat digunakan yaitu dengan memberikan pengajaran yang berorientasi kognitif membangun pengetahuan agama seputar ibadah yang berdampak pada amalan sehari-hari.

Untuk dapat mendirikan lembaga pendidikan berbasis Islam-Kemasyarakatan maka dapat digunakan metode Mean-Ways- end Analysis. Mean yang dimaksud adalah apa saja yang dibutuhkan oleh lembaga ini, maka dapat dibuat semacam tabel kebutuhan : pendanaan, kurikulum, SDM, dan partisipasi masyararakat. Sedangkan Ways yaitu strategi atau cara yang dapat digunakan untuk mengatasi berbagai macam kebutuhan di atas. Masalah pendanaan dimana penggunaannya untuk tahap awal seperti ; pembangunan, pembuatan kelengkapan administrasi kelembagaan, dan perlengkapan sarpras. Sedangkan untuk tahap lanjut seperti; operasional sekolah, gaji SDM, media pembelajaran, kerja sama, dan lain-lain. Pada tahap awal pendanaan dapat menggunakan cara; swadaya oleh rekan dan kerabat terdekat, bantuan pemerintah. Sedangkan untuk tahap lanjut cara yang dapat digunakan seperti melakukan kerjasama CSR, bantuan pemerintah, swadaya masyarakat, pengembangan usaha sekolah, bantuan Dana Desa, orang tua siswa. Cara diatas dapat digunakan salah satunya, dengan memilih alternatif mana yang paling baik untuk segera ditindak lanjuti. Kurikulum sekolah berbasis IslamKemasyarakatan dapat disusun melalui bantuan konsultan sekolah, dengan dibantu masyarakat umum, sedangkan penggagas atau pendiri hanya membuatkan beberapa rambu-rambu kurikulum. Dilibatkannya jasa konsultan kurikulum yaitu mempertimbangkan efektififitas waktu dan ketajaman kurikulum yang diharapkan karena dikerjakan oleh ahlinya. Sedangkan tanpa melibatkan konsultan dan hanya mengandalkan SDM guru baru akan menyulitkan dalam eksekusi pembelajara karena belum tentu guru baru memiliki pengalaman teknis pada persoalan kurikulum. 
Kemudian untuk mendapatkan SDM yang diharapkan, akan mulai dilakukan rekutmen guru dengan kriteria tertentu, seperti mempunyai kecakapan dalam hardskill dan softskill, Islami, berpengetahuan agama, punya jiwa sosial, bergabung dalam kepengurusan desa, dan lain-lain. Selain itu, sekolah juga akan melibatkan tokoh masyarakat untuk masuk dalam beberapa kegiatan pembelajaran seperti pengenalan program desa dan kegiatan-kegiatan sosial lainnya. Kepala desa juga dapat terlibat menjadi bagian dari sekolah untuk membantu baik proses pembelajaran maupun dalam kebijakan-kebijakan tingkat desa. Konsep sekolah yang bermasyarakat membutuhkan partisipasi masyarakat, untuk itu diperlukan penyambutan yang baik dari masyarakat sekitar terhadap seluruh proses pembelajaran. Cara yang dapat digunakan adalah dengan melakukan kerjasama dengan aparat desa, sosialisasi kepada masyarakat, kerjasama dengan kelompok kerja desa (kelompok tani, PKK, dan lain-lain). Diharapkan dengan pengertian dan kerjasama yang baik para siswa dapat melakukan pembelajaran dengan masyarakat dalam berbagai bidang, seperti pertanian, perdagangan, kerajinan, dan lain-lain. Melalui serangkaian aktifitas baik secara kelembagaan dan kurikulum diharapakan dapat mencapai end. Analisis terhadap hasil output dapat dilihat pada tiap tahun dan apa akhir jenjang sekolah. Apakah akan ada perbaikan dan penambahan terhadap seluruh proses atau tidak bergantung pada hasil evaluasi dan analsisis secara menyeluruh. 


\section{KESIMPULAN}

Model perencanaan dapat diartikan sebagai pola atau contoh atau acuan yang digunakan dalam penyusunan sebuah perencanaan. Sedangkan metode perencanaan diartikan sebagai cara atau langkah atau strategi yang ditempuh dalam penyusunan sebuah perencanaan. Ada beberapa model perencanaan pendidikan, yaitu:

1. Perencanaan komperhensif

2. Target setting

3. Costing dan efektifitas biaya

4. Model planning, programming, dan budgeting system

Dalam perencanaan pendidikan berbasis Islam-Kemasyarakatan dalam hal ini menggunakan model PPBS dalam format yang sederhana. Sedangkan yang dimaksud dengan pendidikan berbasis Islam-Kemasyarakatan adalah sebuah pendidikan yang menyandingkan dengan pelbagai persoalan dimasyarakat, dimana juga memiliki tujuan pokok menjadikan masyarakat lebih Islami dan berkemajuan. Untuk itu perlu disusunlah berbagai macam cara untuk dapat merealisasikan sebuah lembaga pendidikan sebagaimana dimaksud. 


\section{DAFTAR PUSTAKA}

Ali Abdul Halim Mahmud, Fikih Responsibilitas dan tanggung Jawab Muslim, Jakarta, Gema Insani Press, 2000, Hlm. 194-195.

Aziz, A., \& Saihu, S. (2019). Interpretasi Humanistik Kebahasaan: Upaya Kontekstualisasi Kaidah Bahasa Arab. Arabiyatuna: Jurnal Bahasa Arab, 3(2), 299-214

Conyers \& Hills, Creative Human Resource Planning and Applications : A Strategic Approach. New York Prectice Hall, Inc, 1994.

Dr. Manap Somantri, M.Pd, Perencanaan Pendidikan, (Bogor: IPB Press, 2014)

Fattah Nanang dalam Endin Mujahidin Dkk, Perencanaan Pendidikan, Bogor, Program Pasca Srajana UIKA Bogor, 2009, Hlm. 55.

file:///C:/Users/HP/Downloads/TEKNIK\%20DAN\%20MODEL\%20PERENCANAAN\%20PEN DIDIKAN.pdf

Hadari Nawawi. Perencanaan SDM untuk Organiasi Profit. Yogyakarta: Gadjah Mada University. 2001

https://www.researchgate.net/publication/335504424_TEKNIK_DAN_MODEL_PERENCANA AN_PENDIDIKAN

https://www.researchgate.net/publication/335504424_TEKNIK DAN_MODEL_PERENCANA AN_PENDIDIKAN

John R. Kelly. 1993. Leisure. Englewood Cliffs, NJ: Prentice-Hall, Inc.

Mubin, F. (2019). TAFSIR EMANSIPATORIS: PEMBUMIAN METODOLOGI TAFSIR PEMBEBASAN. Mumtaz: Jurnal Studi Al-Quran dan Keislaman, 3(1), 131-151.

Mubin, F. KEADILAN DALAM GENDER: KAJIAN KEPEMIMPINAN WANITA DALAM ISLAM1,

Mubin, F. MODEL-MODEL PEMBELAJARAN BERBASIS MADRASAH DAN KEGIATAN LAIN YANG DIPERLUKAN DI DALAMNYA (FAKTOR PENDUKUNGNYA).

Ronaldo, R., Zulfikar, A., Saihu, Ismail, \& Wekke, I. S. (2020). International relations of the asia pacific in the age of trump. Journal of Environmental Treatment Techniques, 8(1), 244-246.

Şahin, C. RELIGIA. 
Saihu, Aziz, A., Mubin, F., \& Sarnoto, A. Z. (2020). Design of islamic education based on local wisdom (An analysis of social learning theories in forming character through ngejot tradition in bali). International Journal of Advanced Science and Technology, 29(6), 12781293.

Saihu, M. (2019). Urgensi 'Urf dalam Tradisi Male dan Relevansinya dalam Dakwah Islam di Jembrana-Bali. Jurnal Bimas Islam, 12(1), 173-201.

Saihu, M. (2019). Merawat Pluralisme Merawat Indonesia (Potret Pendidikan Pluralisme Agama Di Jembrana-Bali). Deepublish.

Saihu, M. M., \& Aziz, A. (2020). Implementasi Metode Pendidikan Pluralisme Dalam Mata Pelajaran Pendidikan Agama Islam. Belajea; Jurnal Pendidikan Islam, 5(1), 131-150.

Saihu, S. (2019). IMPLEMENTASI MANAJEMEN BALANCED SCORECARD DI PONDOK PESANTREN JAM'IYYAH ISLAMIYYAH TANGERANG SELATAN. Mumtaz: Jurnal Studi Al-Quran dan Keislaman, 3(1), 1-22.

Saihu, S. (2019). KOMUNIKASI PENDIDIK TERHADAP ANAK BERKEBUTUHAN KHUSUS DI SEKOLAH KHUSUS ASY-SYIFA LARANGAN. Andragogi: Jurnal Pendidikan Islam dan Manajemen Pendidikan Islam, 1(3), 418-440.

Saihu, S. (2019). KONSEP MANUSIA DAN IMPLEMENTASINYA DALAM PERUMUSAN TUJUAN PENDIDIKAN ISLAM MENURUT MURTADHA MUTHAHHARI. Andragogi: Jurnal Pendidikan Islam dan Manajemen Pendidikan Islam, 1(2), 197-217.

Saihu, S. (2019). PENDIDIKAN KARAKTER BERBASIS KEARIFAN LOKAL (STUDI DI JEMBRANA BALI). Edukasi Islami: Jurnal Pendidikan Islam, 8(01), 69-90.

Saihu, S. (2019). Pendidikan Pluralisme Agama: Kajian tentang Integrasi Budaya dan Agama dalam Menyelesaikan Konflik Sosial Kontemporer. Jurnal Indo-Islamika, 9(1), 67-90,

Saihu, S. (2019). RINTISAN PERADABAN PROFETIK UMAT MANUSIA MELALUI PERISTIWA TURUNNYA ADAM AS KE-DUNIA. Mumtaz: Jurnal Studi Al-Quran dan Keislaman, 3(2), 268-279,

Saihu, S. (2020). ETIKA MENUNTUT ILMU MENURUT KITAB TA'LIM MUTA'ALIM. $A l$ Amin: Jurnal Kajian Ilmu dan Budaya Islam, 3(1), 99-112.

Saihu, S. (2020). KONSEP PEMBAHARUAN PENDIDIKAN ISLAM MENURUT FAZLURRAHMAN. Andragogi: Jurnal Pendidikan Islam dan Manajemen Pendidikan Islam, 2(1), 82-95.

Saihu, S. (2020). Pendidikan sosial yang terkandung dalam Surat At-Taubah Ayat 7172. Edukasi Islami: Jurnal Pendidikan Islam, 9(01), 127-148.

Saihu, S. (2020). The Effect of Using Talking Stick Learning Model on Student Learning Outcomes in Islamic Primary School of Jamiatul Khair, Ciledug Tangerang. Tarbawi: Jurnal Keilmuan Manajemen Pendidikan, 6(01), 61-68.

Saihu, S., \& Mailana, A. (2019). Teori pendidikan behavioristik pembentukan karakter masyarakat muslim dalam tradisi Ngejot di Bali. Ta'dibuna: Jurnal Pendidikan Islam, 8(2), 163-176.

Saihu, S., \& Marsiti, M. (2019). PENDIDIKAN KARAKTER DALAM UPAYA MENANGKAL RADIKALISME DI SMA NEGERI 3 KOTA DEPOK, JAWA BARAT. Andragogi: Jurnal Pendidikan Islam dan Manajemen Pendidikan Islam, 1(1), 2354.

Saihu, S., \& Rohman, B. (2019). PEMBENTUKAN KARAKTER MELALUI MODEL PENDIDIKAN TRANSFROMATIFE LEARNING PADA SANTRI DI PONDOK 
PESANTREN NURUL IKHLAS BALI. Edukasi Islami: Jurnal Pendidikan Islam, 8(02), 435-452.

Saihu, S., \& Taufik, T. (2019). PERLINDUNGAN HUKUM BAGI GURU. Al Amin: Jurnal Kajian Ilmu dan Budaya Islam, 2(2), 105-116. 